\section{Argamassas com incorporação direta de Materiais de Mudança de Fase: Avaliação do comportamento a baixas e elevadas temperaturas}

\author{
Mortars with direct incorporation of Phase \\ Change Materials: Low and high temperature \\ behavior evaluation
}

Sandra Cunha ${ }^{1}$, Marisa Silva ${ }^{1}$, José Aguiar ${ }^{1}$

\footnotetext{
${ }^{1}$ Universidade do Minho, Departamento de Engenharia Civil, Campus de Azurém, CEP: 4800-058, Guimarães, Portugal e-mail: sandracunha86@gmail.com; martinssilva_marisa@hotmail.com; aguiar@civil.uminho.pt
}

\begin{abstract}
RESUMO
Atualmente, é necessário estudar soluções construtivas com bom comportamento a baixas e elevadas temperaturas, ou seja que as argamassas não percam totalmente a sua resistência quando sujeitas a temperaturas diferentes e mais exigentes do que as temperaturas de operação. No que diz respeito ao conhecimento das capacidades de armazenamento térmico dos materiais de mudança de fase (PCM), foram desenvolvidas quatro composições distintas baseadas em cimento e cinzas volantes, nas quais foram incorporados diretamente diferentes teores de PCM não encapsulado $(0 \%, 5 \%, 10 \%$ e $20 \%)$. Estas composições foram testadas a baixas e elevadas temperaturas $\left(-18^{\circ} \mathrm{C}, 20^{\circ} \mathrm{C}, 200^{\circ} \mathrm{C}, 400^{\circ} \mathrm{C}\right.$ e $\left.600^{\circ} \mathrm{C}\right)$, através de ensaios de gelo-degelo e ensaios de compressão e flexão. Foi possível concluir que a incorporação de PCM não encapsulado originou uma melhoria do comportamento a baixas temperaturas, mantendo um comportamento idêntico ao das argamassas de referência quando submetidas a elevadas temperaturas.
\end{abstract}

Palavras-chave: Argamassas, Material de Mudança de Fase, Incorporação direta, Baixas temperaturas, Elevadas temperaturas.

\begin{abstract}
Currently, it is necessary to study constructive solutions with good behavior to low and high temperatures exposure, namely that the mortar not completely lose their strength when subjected to different and more demanding temperatures than the operating temperatures. Concerning the knowledge of the phase change materials (PCM) thermal storage capacities, four different compositions based in cement and fly ash were developed inserting different contents of non-encapsulated PCM $(0 \%, 5 \%, 10 \%$ and $20 \%)$, by direct incorporation. These compositions were tested to low and high temperatures $\left(-18^{\circ} \mathrm{C}, 20^{\circ} \mathrm{C}, 200^{\circ} \mathrm{C}, 400^{\circ} \mathrm{C}\right.$ and $\left.600^{\circ} \mathrm{C}\right)$, through freeze-thaw and compressive and flexural tests. It was possible to conclude that the incorporation of non-encapsulated PCM leads to an improvement of the behavior to the freeze-thaw tests, maintaining an identical behavior to reference mortars when subjected to high temperatures.
\end{abstract}

Keywords: Mortars, Phase Change Materials, Direct incorporation, Low temperatures, High temperatures.

\section{INTRODUÇÃO}

Atualmente, o aquecimento global é uma grande preocupação da sociedade moderna. As emissões perigosas para a atmosfera tais como o dióxido de carbono $\left(\mathrm{CO}_{2}\right)$, são responsáreis pelos fenômenos climáticos negativos. O setor de construção contribuí significativamente para o consumo global de energia e emissões de gases com efeito estufa. Prevê-se que nos próximos anos os requisitos associados aos consumos de energia e utilização que equipamentos de climatização sejam agravados, uma vez que devem aumentar substancialmente até 2050 [1].

As argamassas são um material de construção extremamente importante devido à sua função e sua relação com a durabilidade e resistência a fatores de deterioração nos edifícios [2]. Os edifícios podem ser su- 
jeitos a várias ações acidentais durante o seu tempo de vida, tais como incêndios e inundações, afetando o desempenho dos materiais que os constituem, em particular das argamassas de revestimento interno. Assim, o estudo do comportamento dos materiais de construção a baixas e elevadas temperaturas é de extrema importância.

A exposição dos materiais de construção a elevadas temperaturas exerce uma enorme influência sobre as suas propriedades, uma vez que, quando submetidos a essa ação, podem exibir comportamentos muito distintos daqueles que exibem em condições normais de operação. Durante um incêndio, é possível verificar um gradiente térmico muito elevado nas camadas superficiais do concreto e os danos térmicos provocados são graves [3]. Atualmente, um grande número de estudos publicados revela uma diminuição nas propriedades mecânicas de materiais à base de cimento após exposição a altas temperaturas [4-6]. Vários esforços foram feitos para melhorar a estabilidade térmica de compósitos de cimento, incorporando diferentes materiais, como cinzas volantes ou escórias de alto forno, demonstrando um bom comportamento e uma melhoria do desempenho dos materiais a elevadas temperaturas, devido à capacidade de retenção de uma resistência residual mais alta e redução das fissuras superficiais [6]. Assim, neste trabalho, decidiu-se usar uma quantidade significativa de cinzas volantes na produção de argamassas.

Por outo lado, o elevado consumo de energia em todo o mundo é um dos principais problemas da sociedade moderna [7], sendo necessário estudar e desenvolver novos materiais de construção com capacidade de resolver ou, pelo menos, minimizar esta problemática. Atualmente existe também uma necessidade crescente de reutilizar subprodutos industriais, de forma a obter uma construção mais sustentável. Assim, é importante o desenvolvimento de argamassas sustentáveis com altos níveis de incorporação de resíduos. A substituição do cimento Portland por cinzas volantes é conhecida como uma medida na reutilização de resíduos industriais [8]. A incorporação simultânea de PCM e cinzas volantes em argamassas consiste numa medida para aumentar a eficiência energética dos edifícios e diminuir a quantidade de resíduos depositados em aterro $[9,10]$.

Atualmente, têm vindo a ser desenvolvidos materiais com funções e desempenho específicos com o intuito de melhorar o comportamento dos edifícios a vários níveis. Assim, surgiram materiais com propriedades melhoradas, tais como as argamassas funcionais dentro das quais surgiram argamassas com melhores propriedades térmicas, cujo principal foco na sua utilização é o aumento da eficiência energética dos edifícios. Assim, os materiais de mudança de fase, denominados na língua inglesa de "Phase Change Materials" (PCM),começaram a despertar o interesse da comunidade científica, uma vez que possuem a capacidade de armazenar e libertar energia. A sua aplicação em produtos da construção permite diminuir e deslocalizar os consumos energéticos, as emissões de gases na atmosfera e os impactos ambientais negativos, tornando os edifícios termicamente mais eficientes e sustentáveis.

Nas últimas décadas, foram realizados vários trabalhos de investigação relacionados com a incorporação de PCM em produtos de construção, a reutilização de cinzas volantes e o impacto de altas temperaturas em materiais cimentícios (argamassas e concretos) [11-25]. Contudo, o comportamento a baixas e elevadas temperaturas de argamassas cimentícias com incorporação direta de PCM não encapsulado e cinzas volantes ainda não foi estudado.

Grande parte das investigações recentes relacionadas com o PCM em produtos de construção utilizaram a técnica de encapsulamento em placas de gesso [26-28], concretos, argamassas [4, 29-31], painéis de PVC, blocos e tijolos [9, 32].

O PCM pode ser incorporado em materiais de construção através de diferentes métodos, sendo estes a incorporação direta, imersão, encapsulamento e estabilização [33]. A incorporação direta é o método mais simples e económico para a utilização do PCM, sendo que o material é diretamente misturado com os materiais de construção durante a sua produção. Contudo, pressupõe-se que apresente algumas desvantagens tais como a afetação dos produtos de hidratação, diminuição da resistência da ligação entre a pasta e agregado, diminuição das propriedades mecânicas e durabilidade. Por outro lado, o material apresenta ainda a possibilidade de deslocar do local em que foi aplicado [34]. No método de imersão, os produtos de construção são mergulhados em PCM líquido, de forma a absorver o material por capilaridade. No entanto, tal como na incorporação direta o PCM pode interferir com os produtos de hidratação dos materiais de construção e afetar as propriedades mecânicas e de durabilidade [34]. Relativamente ao encapsulamento, o PCM é encapsulado antes da sua incorporação em produtos de construção, garantindo-se que este não se desloca do local em que foi aplicado durante a fase líquida. A contenção do PCM deve atender a requisitos de resistência mecânica, flexibilidade, resistência à corrosão e estabilidade térmica, assim como agir como uma barreira de proteção. Deve também possuir superfície suficiente para a transferência de calor, assegurar a estabilidade estrutural e o fácil manuseio do material [35]. Existem duas principais formas de encapsulamento: microencapsulamento 
e macroencapsulamento [36]. O macroencapsulamento baseia-se na introdução de PCM em tubos, painéis ou outro recipiente de grandes dimensões, geralmente recipientes com mais de $1 \mathrm{~cm}$ de diâmetro. Nesta técnica é possível colocar uma quantidade significativa de PCM (vários litros) num único recipiente. As principais vantagens deste método são a facilidade de transporte e manuseio, a possibilidade do encapsulamento ser concebido especificamente para a aplicação pretendida, melhor compatibilidade com o material e redução das alterações de volume externas [33, 36]. Como desvantagens podem enunciar-se a baixa condutividade térmica, necessidade de proteção dos elementos de contenção contra a destruição e possibilidade de solidificação do PCM nos cantos e arestas, diminuindo assim a transferência de calor [33]. O microencapsulamento consiste na colocação de uma pequena massa molecular em pequenas partículas, revestidas por polímeros de elevado desempenho. As microcápsulas podem ser esféricas ou assimétricas e com forma variável, com diâmetro inferior a $1 \mathrm{~cm}$. Contudo, o diâmetro preferencial situa-se entre 1 e $60 \mu \mathrm{m}$. A vantagem deste processo de encapsulamento consiste na melhoria da transferência de calor, através da sua grande superfície específica $[25,34,36]$.

CUNHA et al. $[9,37,38]$ desenvolveram vários estudos sobre a incorporação de microcápsulas de PCM em argamassas à base de diferentes ligantes (cimento, cal aérea, cal hidráulica e gesso). Tendo sido possível observar uma diminuição do comportamento mecânico das argamassas (resistência à flexão, resistência à compressão e aderência), assim como aumento da micropososidade e desempenho térmico, evidenciados pela diminuição das necessidades de climatização. No entanto, o custo do PCM microencapsulado é muito elevado, o que dificulta a aplicação prática desta tecnologia. A técnica de encapsulamento apresenta algumas desvantagens relacionadas com o custo de aquisição do PCM e tempo de produção dos materiais de construção. Na técnica de microencapsulamento, o PCM é adicionado aos materiais de construção numa microcápsula polimérica com dimensões inferiores a $60 \mu \mathrm{m}$. Por outro lado, a técnica de incorporação direta consiste em adicionar o PCM em materiais de construção de forma livre, sem qualquer tipo de encapsulamento, representando uma maneira simples e econômica de utilizar o PCM em soluções construtivas.

No que diz respeito à utilização simultânea de PCM e cinzas volantes, a bibliografia não é extensa e estes são apenas relacionados com a utilização de microcápsulas de PCM [39]. Assim, torna-se importante o estudo e desenvolvimento de materiais de construção funcionais baseados em técnicas simples, matériasprimas económicas e sustentáveis, com alto potencial de desempenho térmico e reutilização de resíduos industriais. A utilização da incorporação direta de PCM não encapsulado aparece como uma solução possível para minimizar o elevado consumo energético a baixo custo. Por outro lado, a utilização de resíduos industriais também permite reduzir os custos relacionados com as matérias-primas. Embora nos estudos realizados com os materiais de mudança de fase, a utilização da técnica de incorporação direta ainda permaneça um assunto pouco desenvolvido, a incorporação de PCM não encapsulado adicionado diretamente às argamassas, aparece como um método inovador e promissor para diminuir a dependência energética dos edifícios.

É extremamente importante avaliar o comportamento das argamassas com incorporação de PCM não encapsulado em várias gamas de temperatura, que podem ocorrer em caso de desastre ou acidente. Assim, o principal objetivo deste trabalho consiste na determinação do comportamento de diversas argamassas com incorporação de PCM não encapsulado e puro, quando expostas a baixas temperaturas através de ciclos de gelo-degelo, nos quais se atingiu uma temperatura máxima negativa de $-18^{\circ} \mathrm{C}$ e a elevadas temperaturas através de ensaios de determinação da resistência à compressão e flexão a $200^{\circ} \mathrm{C}, 400^{\circ} \mathrm{C}$ e $600^{\circ} \mathrm{C}$. A seleção da gama de temperatura foi realizada com base na premissa de observar o comportamento das argamassas em temperaturas muito diferentes das temperaturas normais de operação.

\section{METODOLOGIA EXPERIMENTAL}

\subsection{Materiais}

A seleção dos materiais utilizados nesta investigação teve em consideração trabalhos anteriores desenvolvidos pelos próprios autores relacionados com a incorporação de PCM e em argamassas de revestimento interior $[9,10,37]$. Os materiais utilizados foram cimento Portland, cinzas volantes, agregados (areia A e areia B) e PCM não encapsulado. As densidades dos diferentes materiais utilizados encontram-se na Tabela 1. O agregado utilizado foi composto por duas areias A e B, com tamanho médio de partícula de 439,9 $\mu \mathrm{m}$ e 762 $\mu \mathrm{m}$, respetivamente (Figura $1 \mathrm{e} 2$ ). As duas areias foram utilizadas de forma a obter uma curva granulométrica mais extensa. O PCM selecionado foi uma parafina pura com temperatura de transição compreendida entre $20-23^{\circ} \mathrm{C}$ e uma entalpia de $200 \mathrm{~kJ} / \mathrm{kg}$. 
Tabela 1: Densidade dos materiais utilizados.

\begin{tabular}{c|l}
\hline MATERIAL & DENSIDADE \\
\hline CEM II B-L 32.5N & $3030 \mathrm{~kg} / \mathrm{m}^{3}$ \\
\hline Cinzas Volantes & $2420 \mathrm{~kg} / \mathrm{m}^{3}$ \\
\hline Areia A & $2600 \mathrm{~kg} / \mathrm{m}^{3}$ \\
\hline Areia B & $2569 \mathrm{~kg} / \mathrm{m}^{3}$ \\
\hline PCM & $760 \mathrm{~kg} / \mathrm{m}^{3}$ (estado sólido) \\
\cline { 2 - 2 } & $700 \mathrm{~kg} / \mathrm{m}^{3}$ (estado líquido) \\
\hline
\end{tabular}

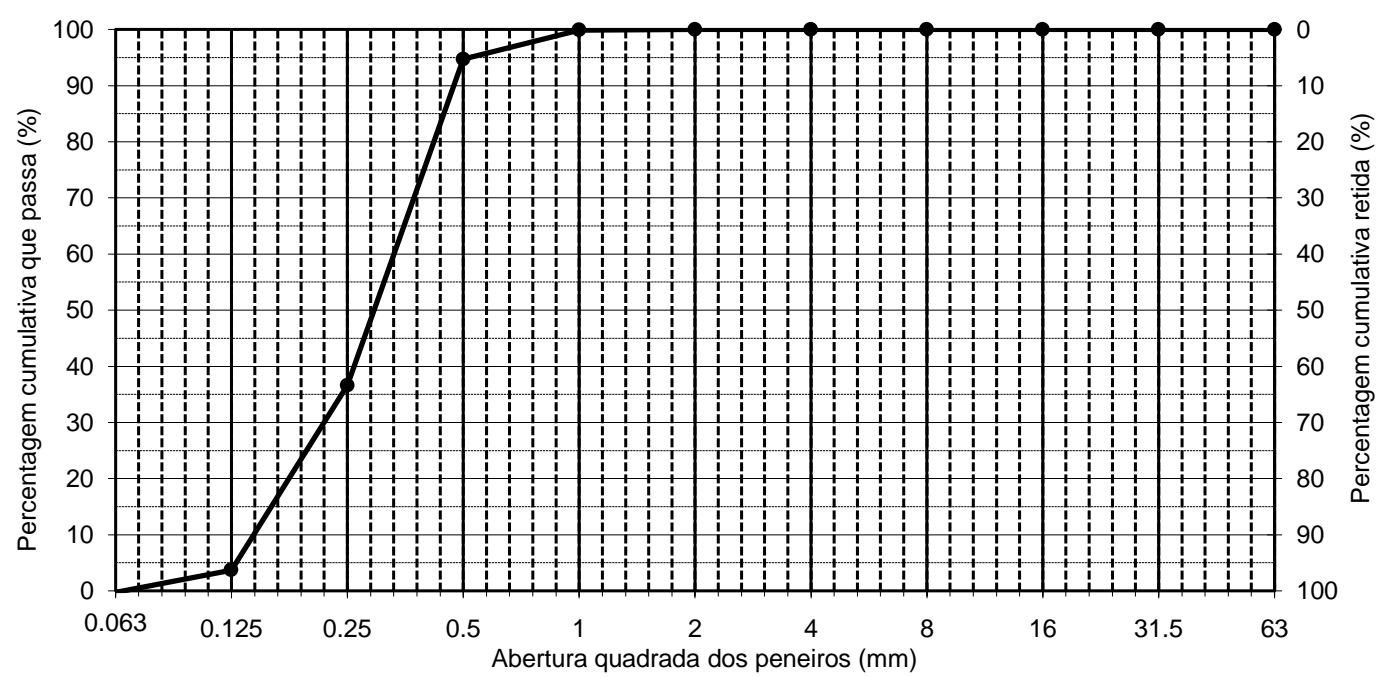

Figura 1: Distribuição granulometrica da areia A.

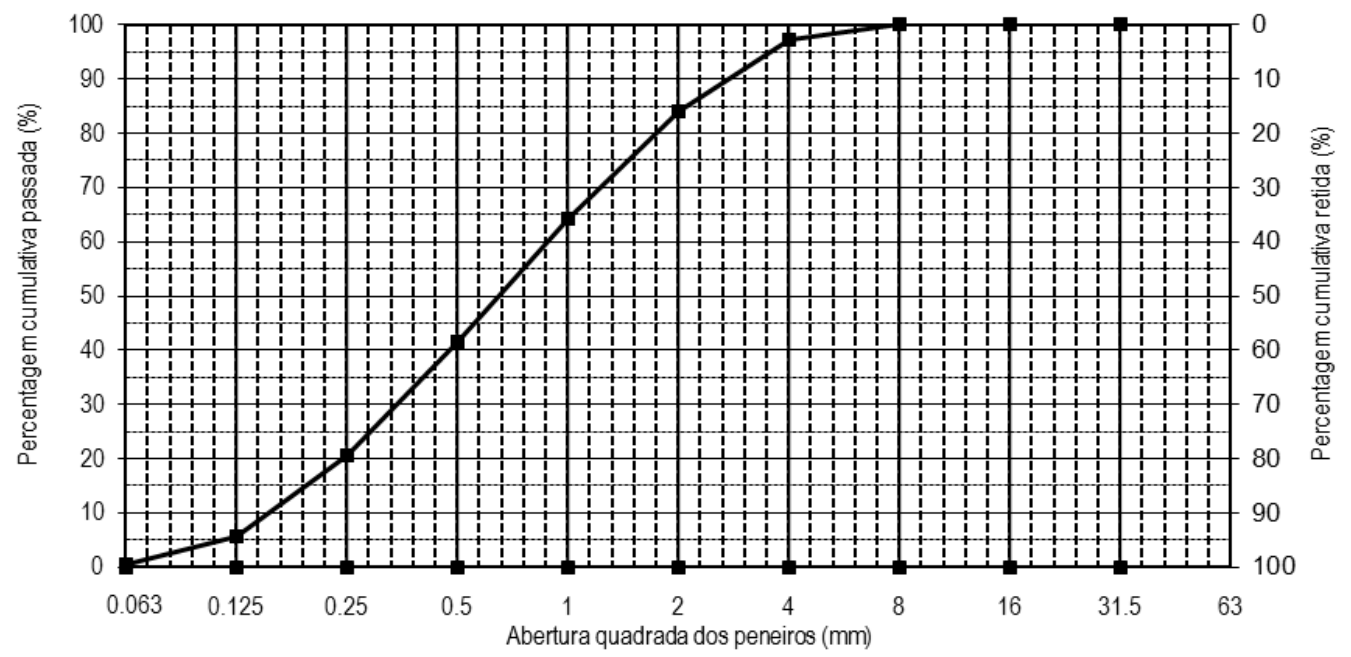

Figura 2: Distribuição granulometrica da areia B.

\subsection{Formulações}

Foram desenvolvidas e estudadas quatro argamassas de cimento distintas, preparadas com diferentes teores de PCM livre, ou seja puro e não encapsulado $(0 \%, 5 \%, 10 \%$ e $20 \%$ ) (Tabela 2). A incorporação de PCM foi realizada em substituição do agregado. O agregado utilizado foi composto por $50 \%$ de areia A e $50 \%$ de areia B. Por sua vez, o ligante foi composto por $40 \%$ de cimento e $60 \%$ de cinzas volantes. A seleção deste ligante 
teve por base a melhoria da estabilidade térmica [6] e o efeito de regulação térmica das argamassas cimentícias [9]. É importante notar que as argamassas desenvolvidas irão ter como função o revestimento de superfícies no interior dos edifícios, desta forma a classificação CSII segundo a especificação NP EN 998-1: 2010 [40] é suficiente para a aplicação pretendida. Assim, foi possível incorporar elevados teores de cinzas volantes sem comprometer o desempenho mecânico das argamassas. $\mathrm{O}$ desenvolvimento destas formulações teve em consideração trabalhos anteriores desenvolvidos pelos autores relacionados com a incorporação de PCM em argamassas para revestimento interior e dos quais este trabalho é uma consequência [9, 10, 37]. Assim, optou-se por utilizar argamassas à base de cimento, sendo estas tradicionalmente utilizadas na construção na Europa.

Tabela 2: Formulação das argamassas $\left(\mathrm{kg} / \mathrm{m}^{3}\right)$.

\begin{tabular}{ccccccc}
\hline FORMULAÇÃO & CIMENTO & $\begin{array}{c}\text { CINZAS } \\
\text { VOLANTES }\end{array}$ & AREIA A & AREIA B & PCM & ÀGUA \\
\hline CEM-0PCM-NE & 200 & 300 & 659.1 & 659.1 & 0 & 300 \\
\hline CEM-5PCM-NE & 200 & 300 & 583.6 & 583.6 & 58.4 & 275 \\
\hline CEM-10PCM-NE & 200 & 300 & 526.2 & 526.2 & 105.2 & 252.5 \\
\hline CEM-20PCM-NE & 200 & 300 & 442.3 & 442.3 & 176.9 & 215 \\
\hline
\end{tabular}

\subsection{Avaliação experimental}

As argamassas foram testadas com o intuito de avaliar o seu comportamento em condições extremas (elevadas e baixas temperaturas). Foi desenvolvida uma caracterização geral baseada em diferentes ensaios, normas e outros trabalhos, tais como: trabalhabilidade [41], densidade [10], absorção de água por capilaridade [42], absorção de água por imersão [43], microestrutura [4, 9] e termogravimetria (DSC-TGA) [10]. Relativamente ao comportamento a elevadas temperaturas foram realizados ensaios de determinação da resistência à flexão e compressão [44] para diferentes gamas de temperatura $\left(20^{\circ} \mathrm{C}, 200^{\circ} \mathrm{C}, 400^{\circ} \mathrm{C}\right.$ e $\left.600^{\circ} \mathrm{C}\right)$. A seleção da temperatura de $20^{\circ} \mathrm{C}$, encontra-se relacionada com o facto desta ser uma temperatura dentro do intervalo de conforto térmico $\left(18^{\circ} \mathrm{C}\right.$ a $\left.25^{\circ} \mathrm{C}\right)$. Por sua vez, o comportamento a baixas temperaturas foi avaliado atraves de ensaios de gelo-degelo [45].

Para todos os ensaios efectuados foram desenvolvidos 3 elementos de ensaios que foram testados aos 28 dias de idade, tendo a cura sido realizada nos primeiros 7 dias de idade em camara humida e nos seguintes 21 dias em condições de laboratório, tal como é especificado pela norma europeia EN 1015-11 [44]. A dimensão dos elementos de ensaio utilizados foi de $40 \times 40 \times 160 \mathrm{~mm}^{3}$ para a determinação da densidade, absorção de água e determinação da resistência à flexão e compressão de acordo com o especificado nas normas europeias e portuguesas [42-44]. Relativamente aos ensaios de gelo-degelo foram utilizados elementos de ensaio prismáticos com $50 \times 50 \times 50 \mathrm{~mm}^{3}$ [45]. Por último tendo em conta a especificidade dos ensaios de microestrutura e termogravimetria foram moldados elementos de ensaio cilindricos com $1 \mathrm{~cm}$ de altura e de diametro.

\section{RESULTADOS E DISCUSSÃO}

\subsection{Trabalhabilidade}

Os ensaios de trabalhabilidade foram realizados de forma a obter um diametro de espalhamento de $180 \pm 5$ $\mathrm{mm}$, com base no método da mesa de espalhamento, com o intuito de obter a mesma trabalhabilidade para as diferentes argamassas desenvolvidas. Através da análise da Tabela 2 foi possível observar uma diminuição do teor de água com o aumento da incorporação de PCM livre, devido ao fato deste ser incorporado no seu estado líquido, o que aumenta o diâmetro de espalhamento.

A Figura 3 mostra a relação água-ligante presente nas diferentes argamassas. A incorporação de um maior teor de PCM resultou numa diminuição da razão água-ligante. A incorporação de 5\% de PCM originou uma diminuição de cerca de $8 \%$ no teor de água adicionado à argamassa. Esse comportamento encontra-se associado ao fato do PCM ser incorporado no seu estado líquido e poder funcionar como um agente para obter uma argamassa homogênea. A utilização de PCM no estado líquido também é a causa do aumento verificado na razão líquido-ligante para maiores teores de PCM (Figura 4). É de notar que o PCM utilizado é uma parafina, tendo o aspecto e natureza de uma cera. Assim, embora o PCM não funcione como um agente para a hidratação do aglutinante, contribui para obter uma maior trabalhabilidade. 


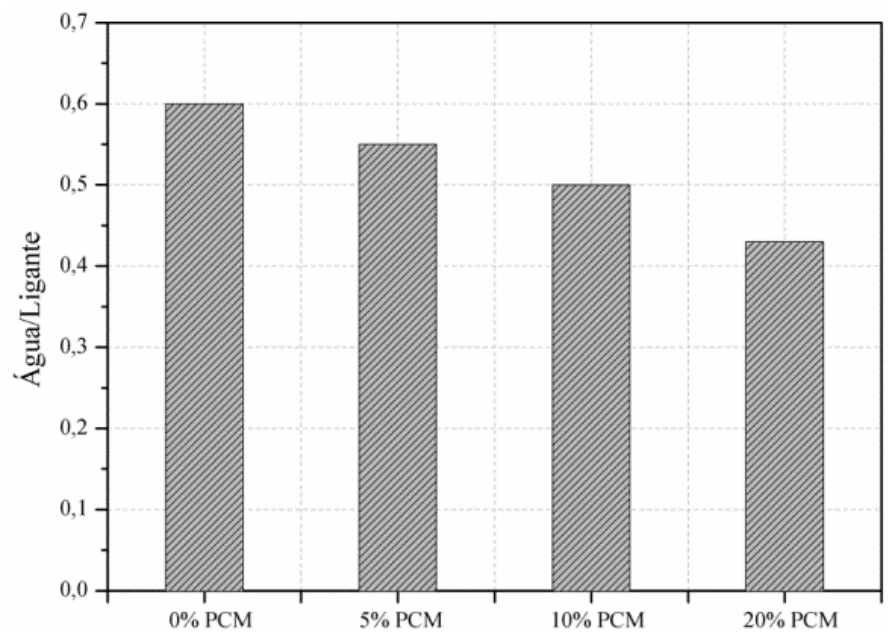

Figura 3: Razão água-ligante da argamassa de referência (0\% PCM) e das argamassas aditivadas com 5\%, $10 \%$ e $20 \%$ de PCM.

\subsection{Densidade}

Relativamente à densidade pode observar-se uma diminuição com a incorporação de PCM não encapsulado (Figura 5). A incorporação de 5\% de PCM não encapsulado origina uma diminuição de cerca de $11 \%$ na densidade das argamassas desenvolvidas, sendo que esta diminuição é ainda mais notória para a incorporação de maiores teores de PCM. Este comportamento encontra-se associado à diminuição da razão água-ligante das argamassas dopadas com PCM, induzida pela adição de PCM não encapsulado no seu estado líquido. Além disso, embora tenha sido previamente estabelecido que o PCM livre pode operar como um agente para conferir uma maior trabalhabilidade, a sua densidade é inferior à densidade da água.

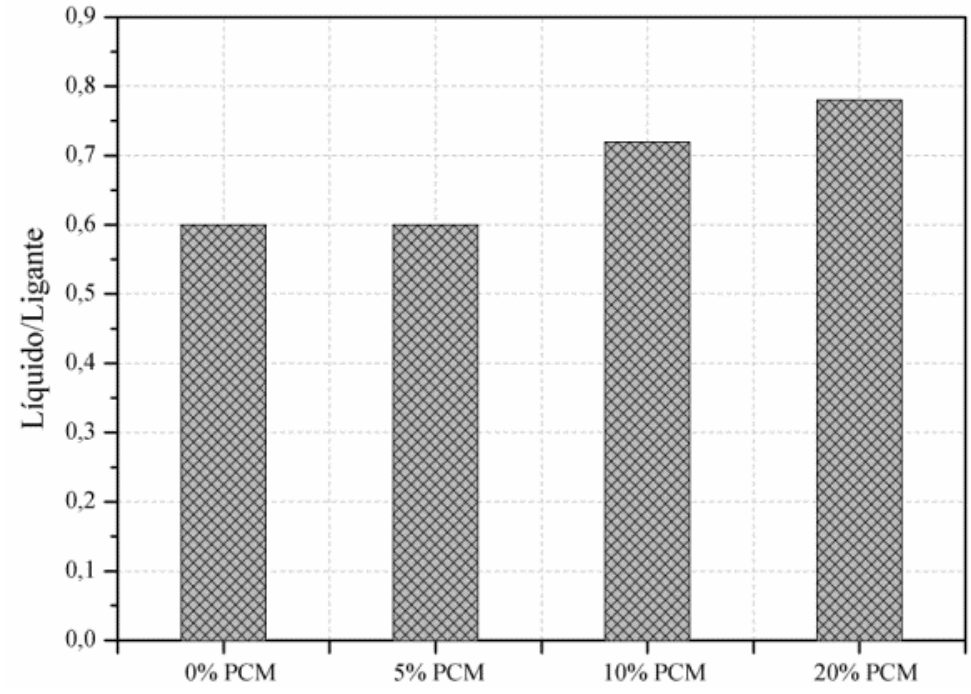

Figura 4: Razão líquido-ligante da argamassa de referência (0\% PCM) e das argamassas aditivadas com 5\%, $10 \%$ e $20 \%$ de PCM. 


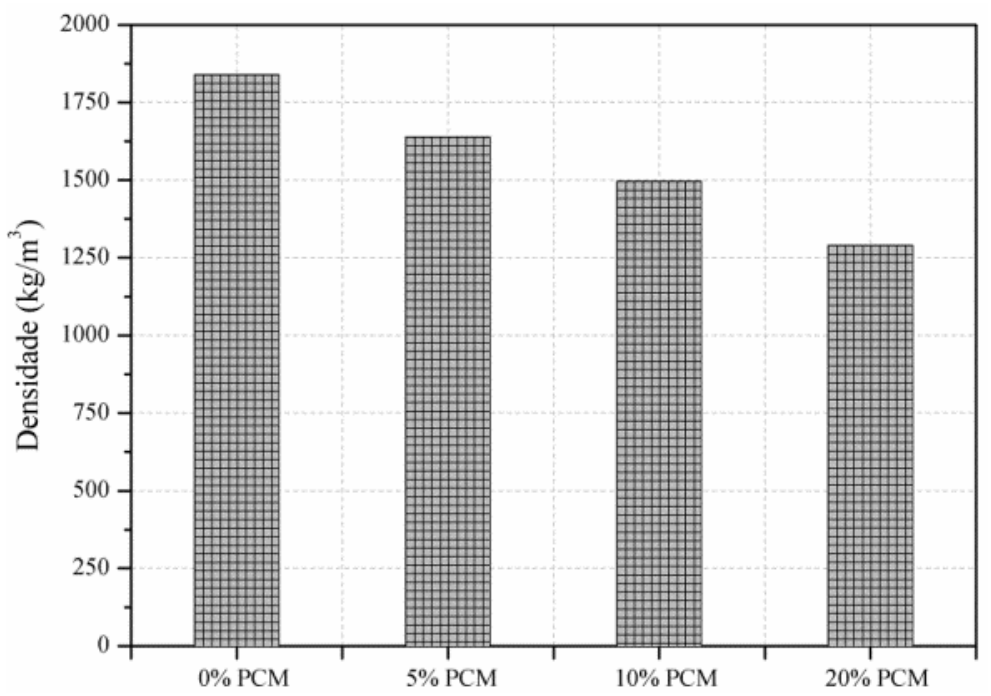

Figura 5: Densidade das argamassas da argamassa de referência (0\% PCM) e das argamassas aditivadas com $5 \%, 10 \%$ e $20 \%$ de PCM.

\subsection{Microestrutura}

As observações microscópicas foram realizadas para todas as argamassas desenvolvidas em duas gamas de temperatura diferentes, $-18^{\circ} \mathrm{C}$ (Figura 6 ) e $20^{\circ} \mathrm{C}$ (Figura 7), com o intuito de observar as argamassas com PCM no estado sólido e no estado de transição, respectivamente.

A Figura 6 revelou uma alteração significativa na microestrutura das argamassas contendo PCM não encapsulado. Na argamassa de referência (Figura 6 a)), observou-se uma microestrutura com cristais em forma de agulha, evidenciada pela presença de uma grande quantidade de cristais de hidratação com forma angular. Contudo, nas argamassas com incorporação de PCM (Figura 6 b) a Figura 6 d)), foi possível identificar uma microestrutura mais compacta, na qual o PCM não encapsulado reveste todos os constituintes da argamassa, fornecendo uma camada protetora dos cristas de hidratação observada na argamassa de referência. $\mathrm{O}$ PCM presente nas argamassas foi completamente agregado aos cristais hidratados e agregados na matriz da argamassa. Assim, também foi possível observar uma diminuição da porosidade das argamassas com incorporação de PCM, o que se torna mais evidente com a incorporação de um maior teor de PCM. Este comportamento pode ser justificado pelo fato do PCM ser adicionado às argamassas durante sua produção na forma líquida, permitindo a sua livre distribuição na matriz das mesmas e o facto deste permanecer ligado às particulas dos materiais constituintes da argamassa.

A Figura 7 mostra a microestrutura das argamassas com incorporação de PCM não encapsulado à temperatura de transição $\left(20^{\circ} \mathrm{C}\right)$. Foi possível observar o mesmo comportamento para as duas gamas de temperatura testadas. No entanto, pode ser observada uma quantidade maior de cristais de hidratação com forma angular (Figura 7 b) a Figura 7 d)), o que indica uma menor quantidade de PCM. Este comportamento pode ser justificado pelo fato de que, a esta temperatura, o PCM permanece em um estado de transição, parte do qual ainda no estado sólido e parte no estado líquido. No entanto, é importante salientar que qualquer material no estado líquido foi removido da amostra por vácuo durante a realização dos ensaios, como consequiência das características e requisitos do equipamento experimental (Microscópio Eletrónico de Varredura). 


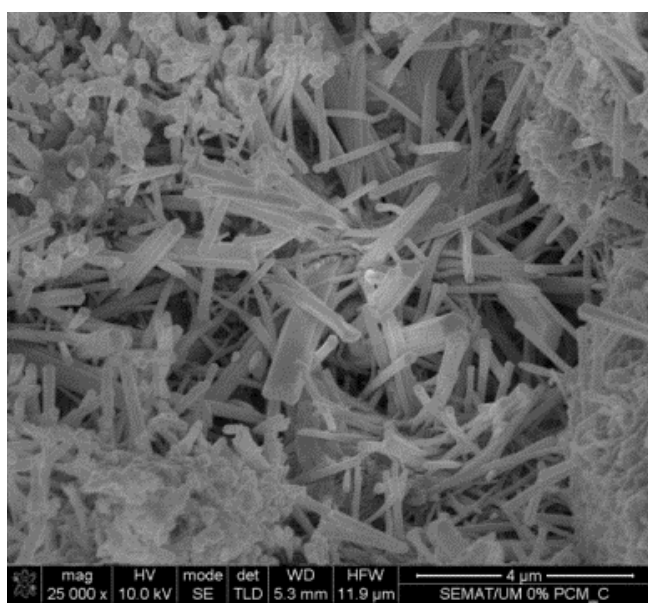

a)

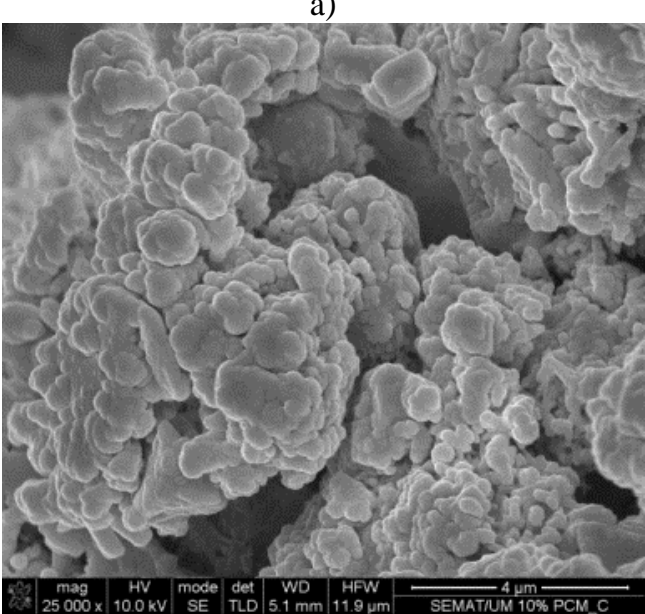

c)

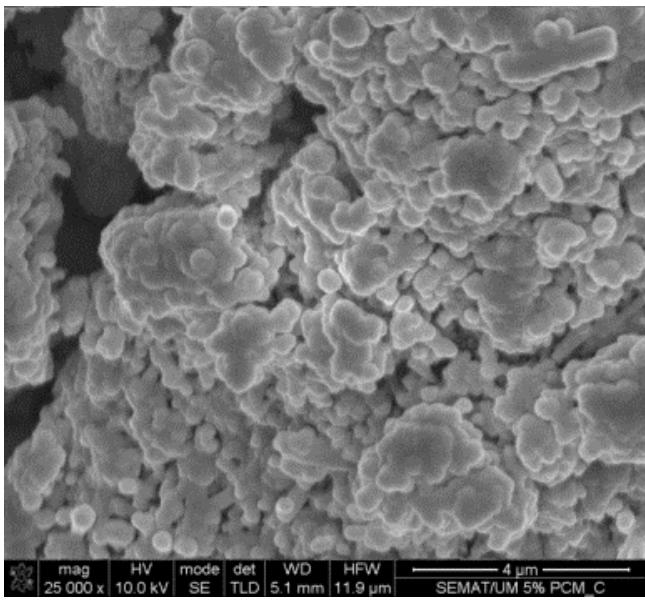

b)

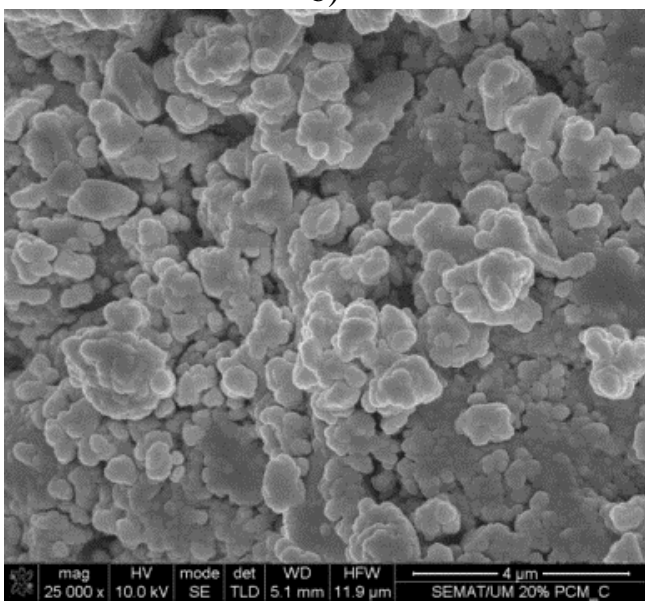

d)

Figura 6: Observações microscópicas realizadas em microscópio electronico, em que os provetes foram mantidos a $-18^{\circ} \mathrm{C}$, com uma ampliação de 25000x: a) Argamassa de referência (0\% PCM); b) Argamassa com incorporação de 5\% de PCM não encapsulado; c) Argamassa com incorporação de $10 \%$ de PCM não encapsulado; d) Argamassa com incorporação de 20\% de PCM não encapsulado.

\subsection{Ensaios de termogravimetria}

Os ensaios de termogravimetria foram realizados com o objetivo de avaliar a influência da adição de PCM não encapsulado nas argamassas. As figuras 8 a 11 mostram as curvas termogravimétricas das diferentes argamassas com diferentes teores de PCM, tendo sido possivel verificar que a incorporação de PCM não encapsulado originou um aumento no número de picos presente nas curvas, o que é justificado pelo atraso do proceso de hidratação com a incorporação de maior teor de PCM. Também é importante observar que os pontos de pico são mais expressivos com a incorporação de teores mais elevados de PCM.

Em relação às argamassas de referência, ou seja sem incorporação de PCM (Figura 8), foi possível identificar dois pontos de pico, sendo estes a $104,3^{\circ} \mathrm{C}$ e $730,4^{\circ} \mathrm{C}$. O primeiro ponto de pico $\left(104^{\circ} \mathrm{C}\right)$ encontrase relacionado com a evaporação da água química não combinada [46]. Geralmente, esta evaporação pode ocorrer até aproximadamente $105^{\circ} \mathrm{C}$ em dois estágios diferentes. O primeiro estágio está relacionado com a evaporação da água não combinada presente nos poros de grandes dimensões da argamassa, ocorrendo tipicamente entre $35^{\circ} \mathrm{C}$ e $70^{\circ} \mathrm{C}$. O segundo estágio diz respeito à água presente nos poros de menores dimensões, os poros capilares, que ocorre entre $70^{\circ} \mathrm{C}$ e $105^{\circ} \mathrm{C}$. O segundo ponto de pico $\left(730^{\circ} \mathrm{C}\right)$ diz respeito à descarbonatação do carbonato de cálcio $\left(\mathrm{CaCO}_{3}\right)$ [10, 46-49]. 


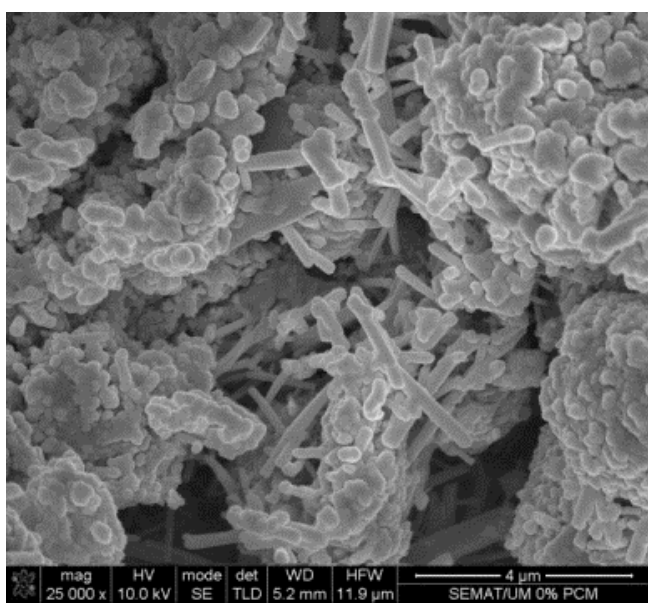

a)

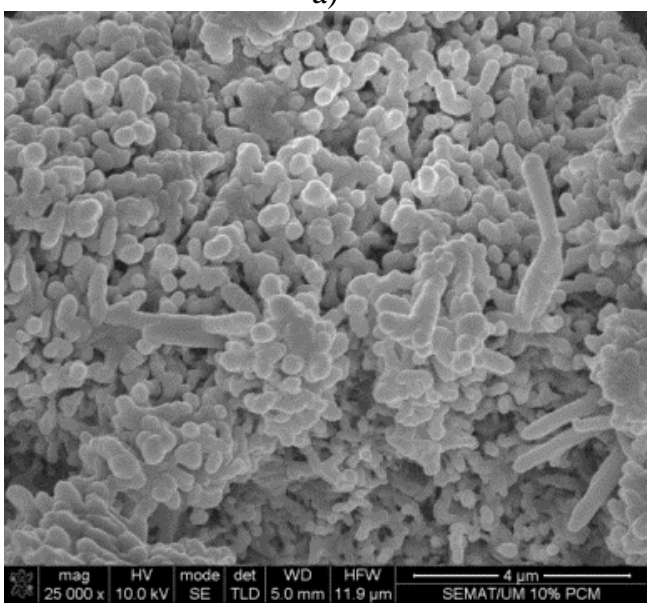

c)

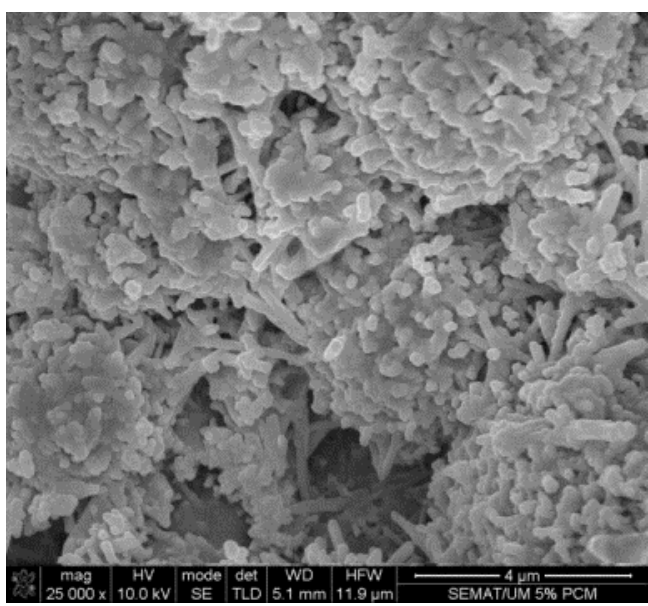

b)

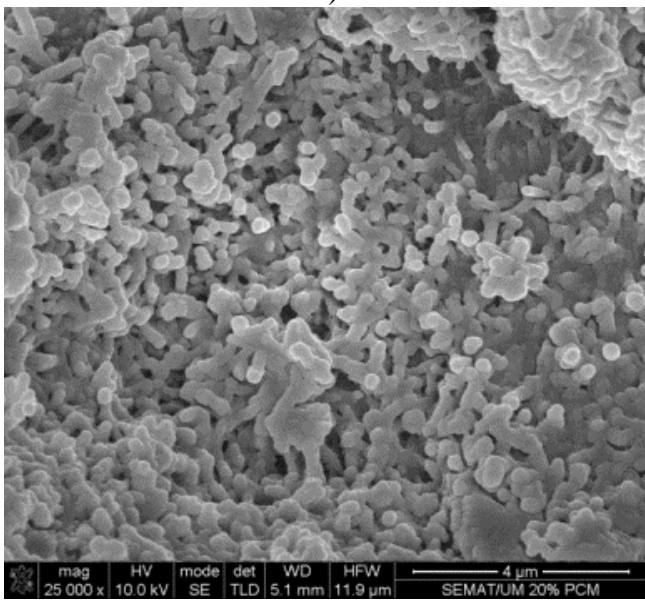

d)

Figura 7: Observações microscópicas realizadas em microscópio electronico, em que os provetes foram mantidos a $20^{\circ} \mathrm{C}$, com um ampliação de 25000x: a) Argamassa de referência (0\% PCM); b) Argamassa com incorporação de 5\% de PCM não encapsulado; c) Argamassa com incorporação de 10\% de PCM não encapsulado; d) Argamassa com incorporação de $20 \%$ de PCM não encapsulado.

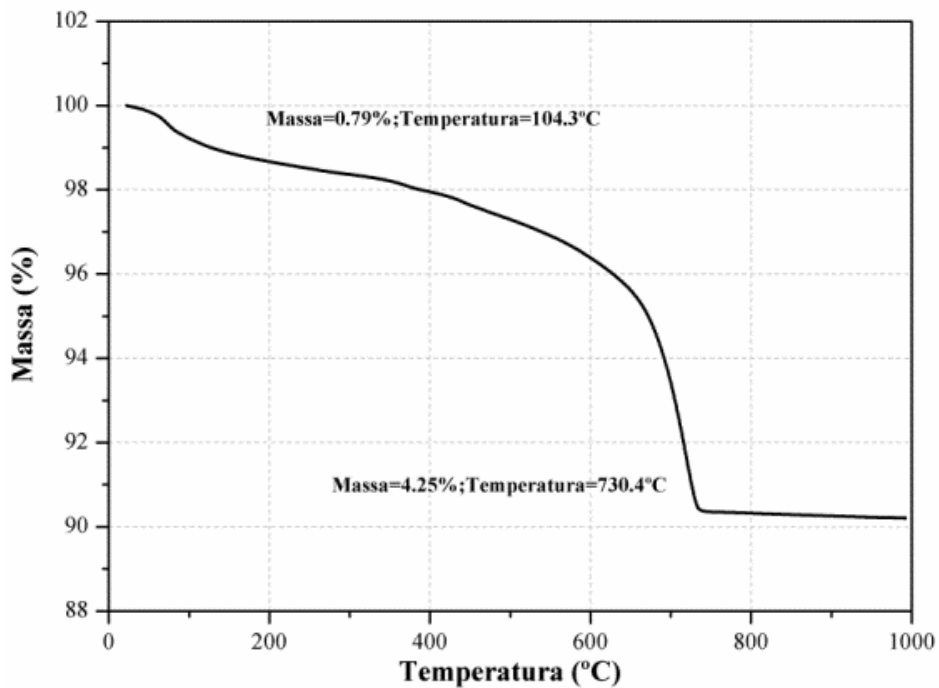

Figura 8: Curva termogravimétrica da argamassa de referência (0\% PCM). 
De acordo com as Figuras 9 a 11, foi possível identificar 4 pontos de pico para as argamassas com incorporação de PCM. Assim, é possivel verificar que a incorporação de PCM livre origina alterações nos produtos de hidratação das argamassas. O primeiro ponto de pico $\left(108,6^{\circ} \mathrm{C}, 104,3^{\mathrm{a}} \mathrm{C}\right.$ e $\left.104,8^{\circ} \mathrm{C}\right)$ diz respeito à evaporação da água química não combinada. $\mathrm{O}$ segundo ponto de pico $\left(200^{\circ} \mathrm{C}, 202,2^{\mathrm{a}} \mathrm{C}\right.$ e $\left.212,2^{\mathrm{a}} \mathrm{C}\right)$, encontrase diretamente relacionado com a presença de PCM, pois corresponde ao ponto de inflamação do PCM [50]. $\mathrm{O}$ terceiro ponto de pico $\left(447,8^{\circ} \mathrm{C}, 437^{\circ} \mathrm{C}\right.$ e $\left.436,9^{\circ} \mathrm{C}\right)$ é relativo à desidroxilação do hidróxido de cálcio $\left(\mathrm{Ca}(\mathrm{OH})_{2}\right)$ [46]. Segundo ANJOS et al. [46], a perda de massa entre $425^{\circ} \mathrm{C}$ e $550^{\circ} \mathrm{C}$, corresponde à decomposição do $\mathrm{Ca}(\mathrm{OH})_{2}$ em óxido de cálcio e água $\left(\mathrm{CaO}+\mathrm{H}_{2} \mathrm{O}\right)$. Finalmente, o quarto ponto de pico $\left(721,7^{\circ} \mathrm{C}\right.$, $719,6^{\circ} \mathrm{C}$ e $\left.723,9^{\circ} \mathrm{C}\right)$ diz respeito à descarbonatação do carbonato de cálcio $\left(\mathrm{CaCO}_{3}\right)[10,46-50]$.

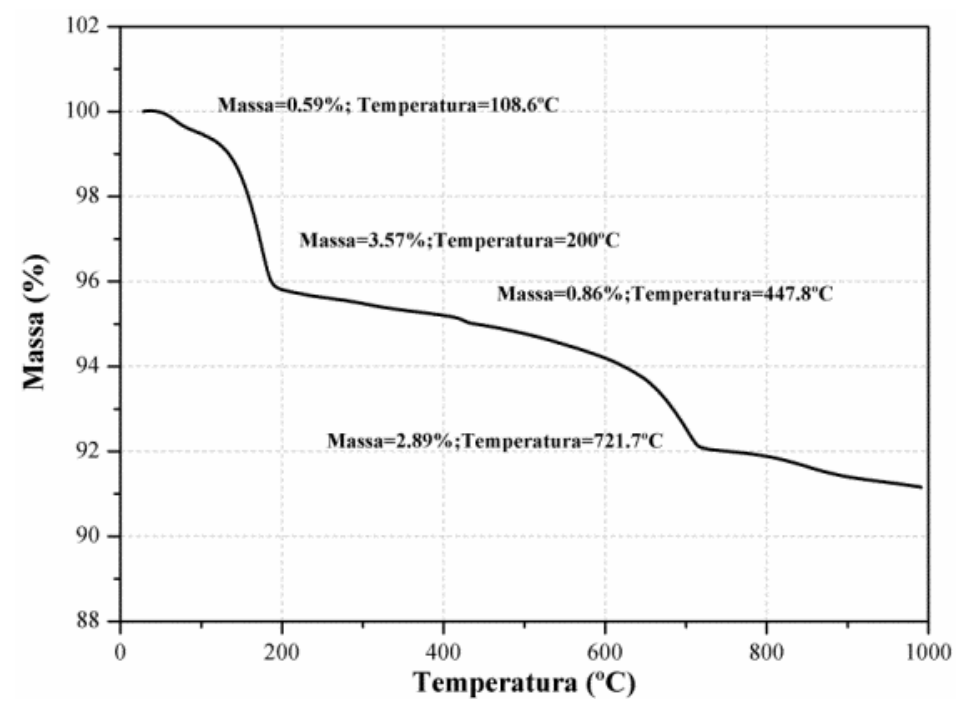

Figura 9: Curva termogravimétrica da argamassa com incorporação de 5\%PCM.

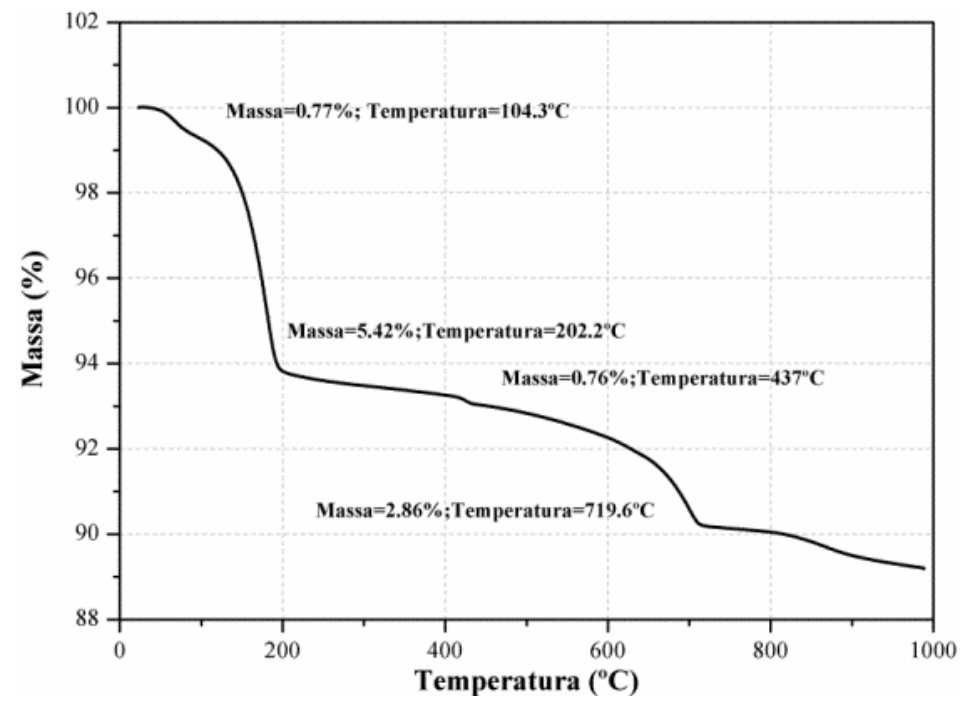

Figura 10: Curva termogravimétrica da argamassa com incorporação de 10\%PCM.

De acordo com os resultados apresentados, foi possivel observar a presença de hidróxido de cálcio nas argamassas dopadas com PCM não encapsulado. Assim, pode inferir-se a existência de um atraso no processo de hidratação do ligante, o que pode ser justificado pelo fato do PCM interferir no contato entre o cimento e água, bem como entre as cinzas volantes e hidróxido de cálcio. A interferência causada pelo PCM no contato entre ligante, água e hidróxido de cálcio pode ser justificada pelo fato de que o PCM não encapsulado reveste livremente toda a matriz da argamassa, permanecendo aderente aos produtos de hidratação do cimento, às cinzas volantes e aos agregados (Figuras 6 e 7). 


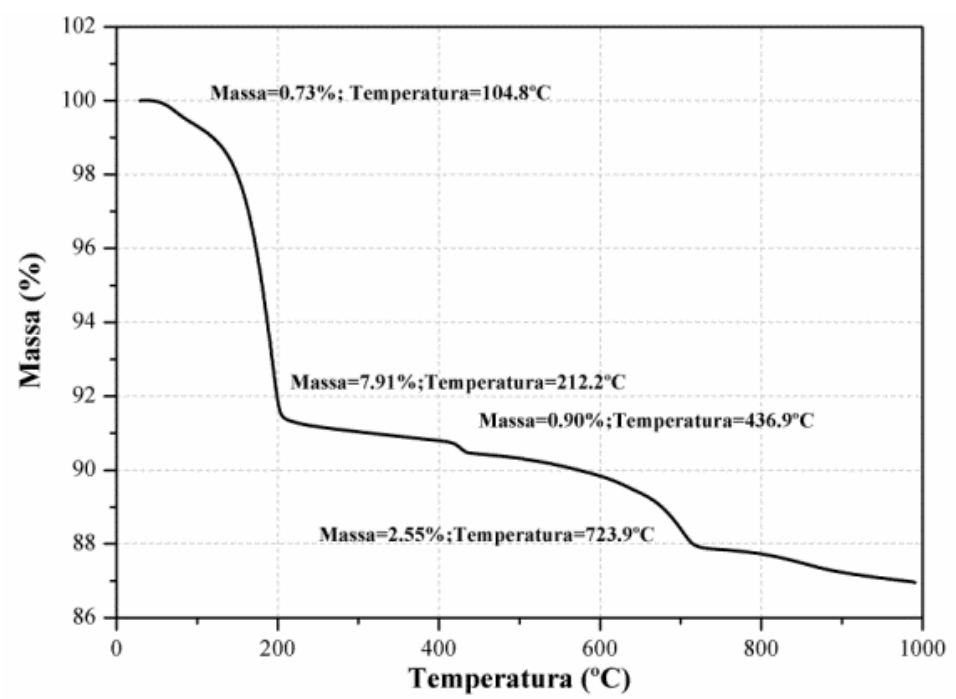

Figura 11: Curva termogravimétrica da argamassa com incorporação de 20\% PCM.

Além disso, é ainda importante notar que a perda de massa associada à desidroxilação do hidróxido de cálcio e descarbonatação do carbonato de cálcio é muito semelhante para todas as argamassas com incorporação de PCM, o que indica que o atraso no processo de hidratação encontra-se diretamente relacionado à presença de PCM e não com o seu teor. Conforme mencionado na Seção 2.2, o PCM foi adicionado à argamassa, substituindo o agregado de acordo com sua massa. Entretanto, para melhor entender os resultados termogravimétricos e a possibilidade de perdas de PCM durante o procedimento, manuseio e cura das argamassas, foi calculada a quantidade de PCM presente em cada argamassa em relação ao material sólido. A Tabela 3 mostra o conteúdo de PCM em relação à massa de materiais sólidos que compõem as argamassas (isto é, cimento, cinzas volantes e areia). A partir desta tabela, pode-se observar facilmente que a incorporação de um maior teor de PCM origina uma maior perda de PCM. De fato, a incorporação de $20 \%$ de PCM não encapsulado leva a uma perda máxima de PCM de cerca de 30\%. Esta situação é consequência do fato da matriz das argamassas atingir a sua capacidade máxima de suporte, uma vez que o PCM fica aderente aos produtos de hidratação e às partículas presentes na microestrutura da argamassa. Por outro lado, teores inferiores de PCM não originam perdas tão significativas.

Tabela 3: Teor de PCM em relação à massa de constituintes sólidos (\%).

\begin{tabular}{ccc}
\hline FORMULAÇÃO & TEOR DE PCM TEÓRICO & TEOR DE PCM REAL \\
\hline CEM-0PCM-NE & 0 & 0 \\
\hline CEM-5PCM-NE & 3.38 & 3.57 \\
\hline CEM-10PCM-NE & 6.34 & 5.42 \\
\hline CEM-20PCM-NE & 11.3 & 7.91 \\
\hline
\end{tabular}

\subsection{Absorção de água}

O comportamento das argamassas quando sujeitas a condições de operação anormais, assim como a sua durabilidade, é bastante afetado pela capacidade de absorção de água, uma vez que esta se encontra diretamente relacionada com a facilidade de penetração de agentes agressivos nas mesmas. De fato, a capacidade de penetração dos agentes agressivos é influenciada pela razão água-ligante, finura do ligante, trabalhabilidade e condições de cura. Portanto, a absorção de água por capilaridade e imersão são parâmetros de extrema importância, principalmente no caso de argamassas com incorporação de PCM não encapsulado, uma vez que a adição de PCM neste trabalho foi realizada no seu estado líquido e posteriormente armazenado nos poros da argamassa.

\subsubsection{Absorção de água por capilaridade}

A incorporação de PCM não encapsulado nas argamassas originou uma diminuição do coeficiente de absorção de água por capilaridade (Figura 12), sendo que a incorporação de 5\% do PCM induziu uma diminuição 
de cerca de $60 \%$ no coeficiente de absorção de água. Com base na Figura 13 é possivel observar que a incorporação de um maior teor de PCM leva a uma menor capacidade de aborção de água por capilaridade ao longo do tempo. Este comportamento encontra-se associado ao fato do PCM se agregar às partículas constituintes da argamassa, criando uma camada protetora e consequentemente reduzindo os vazios existentes, o que resulta numa diminuição da porosidade. Desta forma, pode concluir-se que o PCM é armazenado na argamassa, evitando riscos associados à alteração da posição pretendida após a sua aplicação em sua fase líquida.

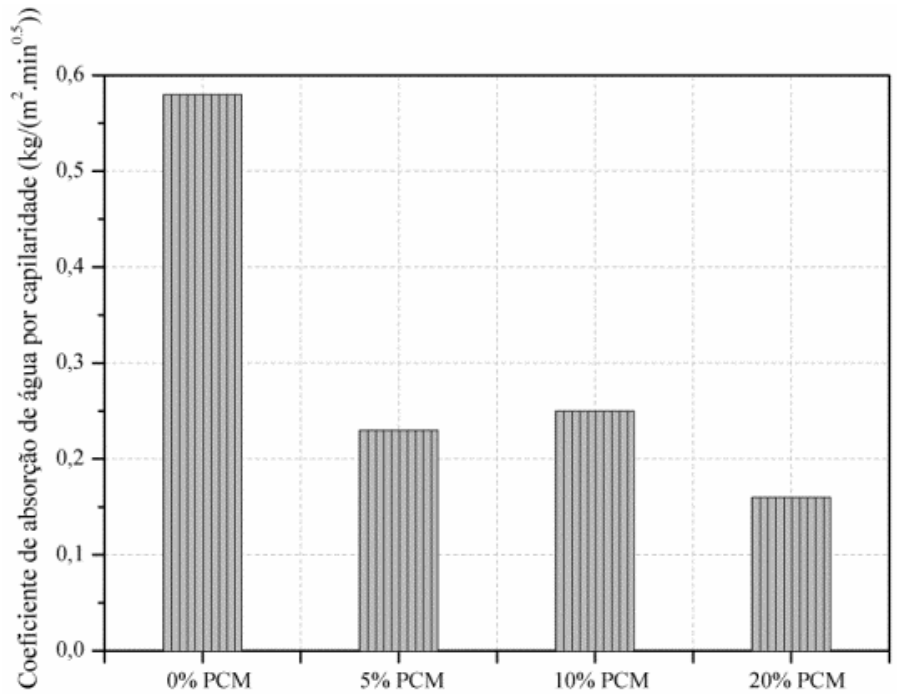

Figura 12: Coeficiente de absorção de água por capilaridade da argamassa de referência ( $0 \%$ PCM) e das argamassas aditivadas com 5\%, 10\% e 20\% de PCM.

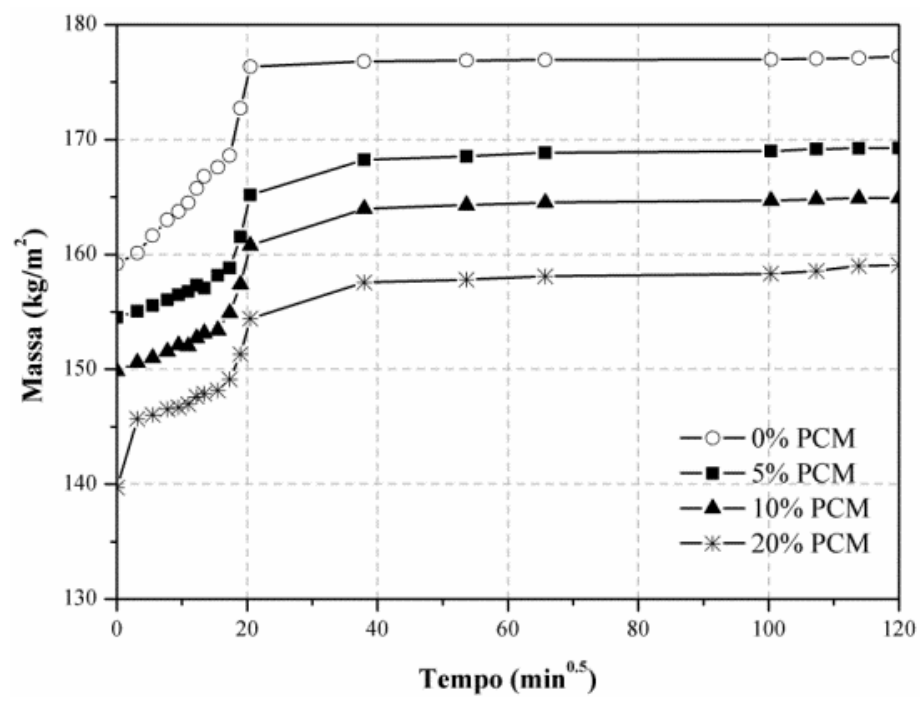

Figura 13: Absorção de água por capilaridade da argamassa de referência (0\% PCM) e das argamassas aditivadas com $5 \%, 10 \%$ e $20 \%$ de PCM.

\subsubsection{Absorção de água por imersão}

Relativamente à absorção de água por imersão foi possível observar uma diminuição de cerca de $18 \%$ com a incorporação de 5\% de PCM não encapsulado (Figura 14). É importante notar que para teores mais elevados de incorporação de PCM observou-se uma redução mais exprssiva na absorção de água por imersão. Desta forma, foi possivel verificar que o PCM puro é armazenado na matriz de argamassa, que constitui uma forma natural de encapsulamento de PCM. 


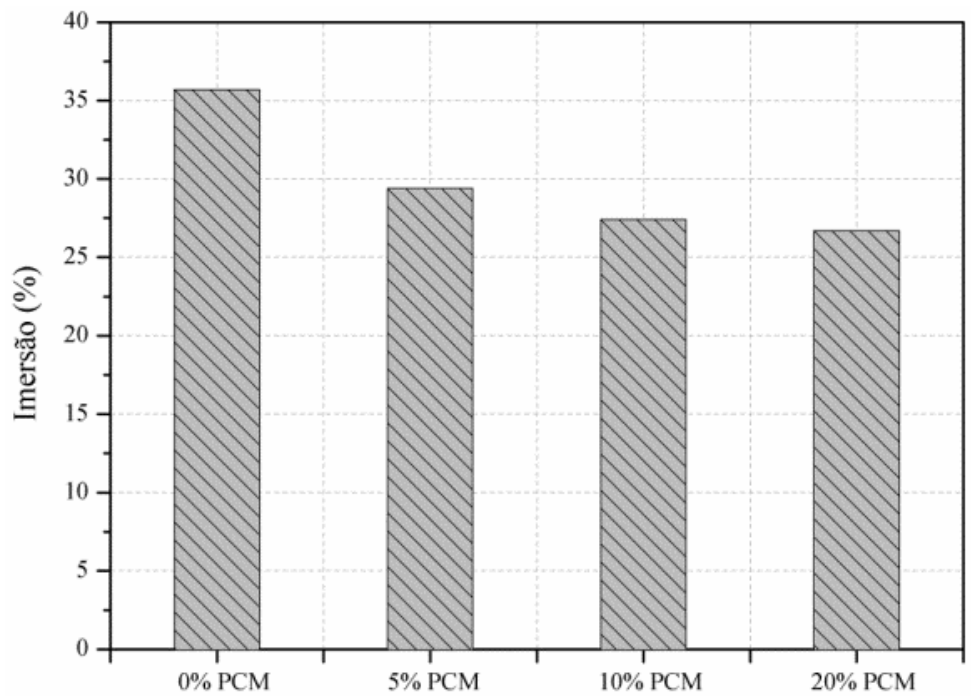

Figura 14: Absorção de água por imersão da argamassa de referência ( $0 \%$ PCM) e das argamassas aditivadas com $5 \%, 10 \%$ e $20 \%$ de PCM.

\subsection{Comportamento a elevadas temperaturas}

O comportamento das argamassas a elevadas temperaturas foi avaliado com base em ensaios de flexão e compressão realizados a diferentes gamas de temperatura, $20^{\circ} \mathrm{C}$ (temperatura de referência), $200^{\circ} \mathrm{C}, 400^{\circ} \mathrm{C}$ e $600^{\circ} \mathrm{C}$. A seleção desta gama de temperaturas teve em consideração a simulação do comportamento das argamassas quando expostas a um incêndio. É importante observar que a submissão das argamassas a temperaturas de $800^{\circ} \mathrm{C}$ originou a destruição dos elementos de ensaio, tanto para as argamassas de referência quanto para as argamassas com incorporação de PCM. O comportamento a elevadas temperaturas foi realizado para argamassas com 28 dias de cura, tendo estas sido submetidas à gama de temperatura correspondente durante quatro horas, com recurso a um mufla.

De acordo com a Figura 15, a incorporação de PCM não encapsulado origina uma leve diminuição na resistência à flexão em todas as gamas de temperatura testadas. Contudo, este comportamento torna-se mais evidente para um teor de incorporação de $20 \%$ de PCM não encapsulado. Pode ainda ser observada uma diminuição mais pronunciada na resistência à compressão das argamassas com a incorporação de PCM. A incorporação de 5\% de PCM resulta numa diminuição na resistência à compressão superior a $20 \%$ para a temperatura de referência $\left(20^{\circ} \mathrm{C}\right)$. Este comportamento pode ser justificado pelo atraso associado às reações de hidratação do ligante e pela presença de uma maior razão de líquido-ligante nas argamassas, uma vez que o PCM é adicionado à argamassa no estado líquido, contribuindo para o aumento da quantidade de poros nas argamassas. No entanto, é importante notar que esses poros encontram-se total ou parcialmente ocupados com PCM, o que origina uma influência pouco significativa na resistência à flexão.
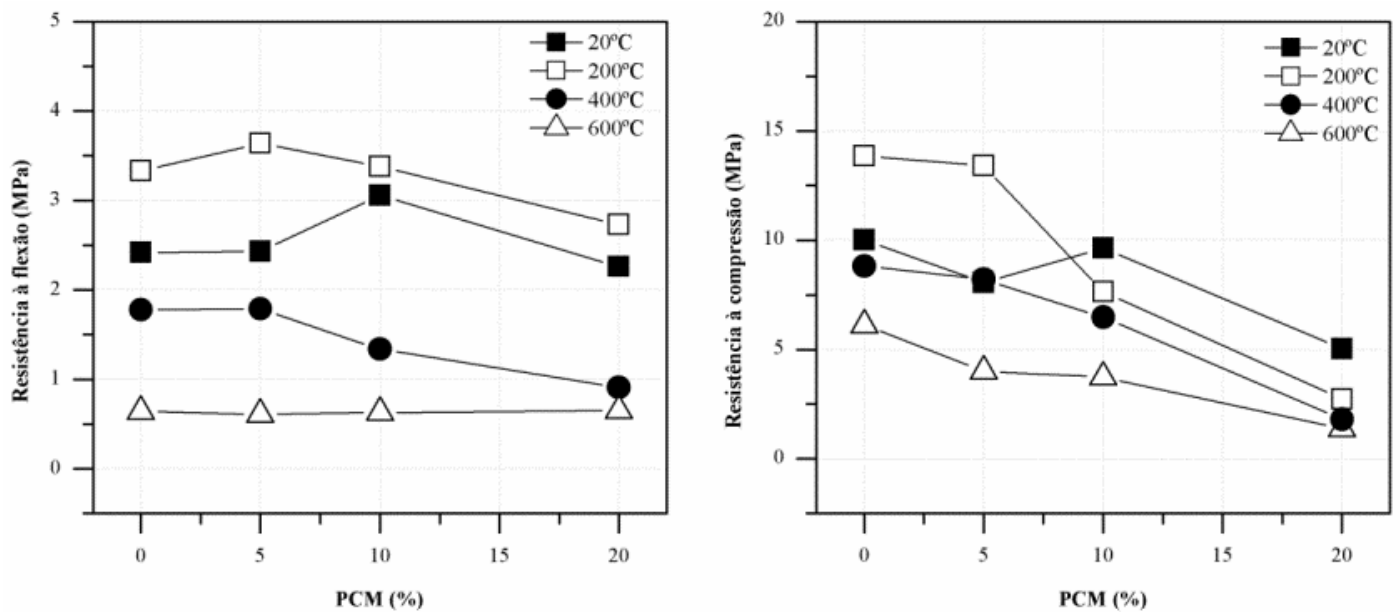

Figura 15: Resistência à flexão e compressãodas argamassas aos 28 dias de hidratação sob ação de elevadas temperaturas. 
Em relação ao efeito da temperatura, pode observar-se que as argamassas submetidas a uma temperatura de $200^{\circ} \mathrm{C}$ apresentam uma melhor comportamento à flexão e compressão, comparativamente com a temperatura de referência $\left(20^{\circ} \mathrm{C}\right)$. Este fenômeno pode ser justificado pelo fato da temperatura acelerar o processo de hidrtação dos materiais cimentícios. No entanto, a exposição das argamassas cimentícias a temperaturas superiores $\left(400^{\circ} \mathrm{C} \mathrm{e} 600^{\circ} \mathrm{C}\right)$ originou uma diminuição significativa no seu comportamento à flexão e à compressão. Sendo que, verificou-se uma diminuição na resistência à flexão superior a $26 \%$ e $71 \%$ para uma exposição de $400^{\circ} \mathrm{C}$ e $600^{\circ} \mathrm{C}$, respectivamente. Da mesma forma, a resistência à compressão das argamassas sofreu uma redução superior a $12 \%$ para uma exposição de temperatura de $400^{\circ} \mathrm{C}$ e $39 \%$ para uma exposição de temperatura de $600^{\circ} \mathrm{C}$, em comparação com a temperatura de referência $\left(20^{\circ} \mathrm{C}\right)$. Este comportamento encontra-se relacionado com o desenvolvimento de microfissuras nas argamassas, originadas pela elevada pressão de vapor interno e pelo gradiente térmico entre as camadas internas e externas das amostras [4, 51, 52]. Estas microfissuras originam uma diminuição na área de resistência da seção transversal, resultando num impacto negativo para a resistência à flexão e compressão [53]. Por outro lado, é importante observar que a exposição das argamassas cimentícias a uma gama de temperatura compreendida entre $425^{\circ} \mathrm{C}$ a $550^{\circ} \mathrm{C}$ leva a uma decomposição do hidróxido de cálcio $\left(\mathrm{Ca}(\mathrm{OH})_{2}\right)$ em óxido de cálcio e água $\left(\mathrm{CaO}+\mathrm{H}_{2} \mathrm{O}\right)$, o que também causa uma redução das forças mecânicas [46, 54].

\subsection{Comportamento a baixas temperaturas}

$\mathrm{O}$ comportamento a baixas temperatura nas argamassas foi baseado em ensaios de gelo-degelo. As argamassas foram submetidas a 56 ciclos de teste, após 28 dias de cura, sendo que a duração de cada ciclo foi de 24 horas e a temperatura variou de $-18^{\circ} \mathrm{C}$ a $24^{\circ} \mathrm{C}$. A degradação sofrida pelas argamassas foi medida levando em consideração as perdas de massa sofridas em cada ciclo.

Os ensaios de gelo-degelo consistem em submeter as amostras a ciclos de temperaturas positivas e negativas. Quando ocorrem temperaturas negativas, a água dentro da argamassa congela e, consequentemente, aumenta seu volume. Embora o risco seja reduzido nos casos em que os poros das argamassas não estejam saturados (ou seja, o volume de água congelada seja inferior ao volume dos poros), nos casos em que a saturação foi atingida, o aumento do volume resultante do processo de congelamento origina pressões nas paredes dos poros (isto é, na microestrutura das argamassas). Este comportamento pode levar à destruição parcial dos elementos de ensaio. Por sua vez, durante todo o processo de degelo, a quantidade de água anteriormente cristalizada retoma seu volume inicial. No decorrer desse processo, duas situações diferentes podem ocorrer: a secagem parcial ou total das amostras devido à mudança de fase para gás e a absorção de uma nova quantidade de água por capilaridade.

A Tabela 4 mostra o comportamento das argamassas durante os ciclos de gelo-degelo. A argamassa com incorporação de 20\% de PCM não encapsulado apresenta uma maior resistência à ação de gelo-degelo, uma vez que não mostra uma perda de massa significativa nos primeiros ciclos do teste. Por outro lado, a argamassa mais sensível a esse tipo de agressão é a argamassa sem incorporação de PCM, pois apresenta uma perda completa dos elementos de ensaio durante os primeiros ciclos de teste. Foi possível também observar que a perda de massa foi menos significativa e mais lenta para as argamassas com incorporação de PCM. Além disso, a perda total da argamassa com incorporação de $20 \%$ de PCM ocorre no ciclo 65 e a perda de massa total da argamassa de referência (0\% PCM) ocorre no ciclo 22. Este comportamento revela que a incorporação de material de mudança de fase levou a menores perdas de material durante a ação do degelodegelo, demonstrando que a incorporação de PCM não encapsulado aprimora as argamassas de forma a que estas se tornem menos suscetíveis a este tipo de ação, o que se encontra relacionado com a menor relação água-ligante presente nas argamassas com incorporação de PCM, juntamente com uma diminuição nas dimensões e quantidade de poros na matriz da argamassa.

Tabela 4: Perda de massa durante o ensaio de gelo degelo (\%).

\begin{tabular}{ccccc}
\hline CICLO & CEM-0PCM-NE & CEM-5PCM-NE & CEM-10PCM-NE & CEM-20PCM-NE \\
\hline 0 & 0 & 0 & 0 & 0 \\
\hline 2 & 20 & 16 & 20 & 15 \\
\hline 3 & 20 & 16 & 20 & 15 \\
\hline 6 & 20 & 16 & 20 & 15 \\
\hline 7 & 20 & 15 & 20 & 15 \\
\hline 13 & 19 & 15 & 19 & 15 \\
\hline
\end{tabular}




\begin{tabular}{lllll}
\hline 16 & 18 & 14 & 18 & 15 \\
\hline 17 & 21 & 14 & 18 & 15 \\
\hline 20 & 37 & 14 & 18 & 15 \\
\hline 22 & 100 & 13 & 17 & 15 \\
\hline 23 & 100 & 10 & 18 & 15 \\
\hline 28 & 100 & 11 & 30 & 15 \\
\hline 29 & 100 & 45 & 46 & 15 \\
\hline 34 & 100 & 100 & 58 & 15 \\
\hline 35 & 100 & 100 & 59 & 15 \\
\hline 37 & 100 & 100 & 86 & 15 \\
\hline 42 & 100 & 100 & 100 & 15 \\
\hline 43 & 100 & 100 & 100 & 20 \\
\hline 48 & 100 & 100 & 100 & 20 \\
\hline 51 & 100 & 100 & 100 & 28 \\
\hline 57 & 100 & 100 & 100 & 28 \\
\hline 58 & 100 & 100 & 100 & 37 \\
\hline 62 & 100 & 100 & 100 & 53 \\
\hline 65 & 100 & 100 & 100 & 100 \\
\hline & & & & \\
\hline
\end{tabular}

\section{CONCLUSÃO}

Este estudo avaliou o comportamento de argamassas de cimento com incorporação direta de PCM não encapsulado a elevadas e baixas temperaturas, compreendendo um avanço considerável no estado de conhecimento nesta área.

A incorporação de PCM puro e livre originou uma diminuição na relação água-ligante e um aumento na razão líquido-ligante devido ao fato do PCM ser incorporado no seu estado líquido. É importante notar que o PCM pode funcionar como um agente para a obtenção de uma argamassa homogênea, contribuindo para uma maior trabalhabilidade. Além disso, também foi verificada uma diminuição na densidade das argamassas com a incorporação de PCM não encapsulado, o que pode ser explicado pela diminuição da razão água-ligante das argamassas e pela menor densidade que caracteriza o PCM.

No que diz respeito à absorção de água por capilaridade verificou-se uma diminuição no coeficiente de absorção de água, aliado a uma diminuição na absorção de água por imersão nas argamassas com incorporação de PCM não encapsulado. Este comportamento pode ser justificado pelo fato do PCM ocupar parte da microestrutura da argamassa, uma vez que o PCM é retido dentro dos poros da argamassa e conectado à matriz da argamassa, diminuindo a porosidade e ocupando parcial ou totalmente os poros da argamassa.

O comportamento mecânico das argamassas foi afetado pela incorporação de PCM, originando uma diminuição no seu comportamento à flexão e compressão, o que se encontra relacionado com a presença de uma maior relação líquido-ligante nas argamassas com PCM e ao atraso das reações de hidratação do ligante.

No que diz respeito ao comportamento das argamassas com incorporação de PCM não encapsulado quando expostas a elevadas temperaturas $\left(200^{\circ} \mathrm{C}, 400^{\circ} \mathrm{C}\right.$ e $\left.600^{\circ} \mathrm{C}\right)$, foi possível observar uma melhoria no comportamento à flexão e compressão para uma temperatura de $200^{\circ} \mathrm{C}$, devido ao fato da temperatura acelerar as reações de hidratação do cimento e cinzas volantes. No entanto, a exposição a temperaturas mais altas causa uma diminuição significativa no comportamento mecânico das argamassas, resultante do desenvolvimento de microfissuras nas argamassas e a subsequente diminuição da resistência da seção transversal.

Em relação ao comportamento a baixas temperaturas, foi possível verificar uma maior resistência à ação de gelo-degelo, devido à menor relação da água-ligante e porosidade inerente às argamassas dopadas com PCM.

Resumidamente, pode concluir-se que, por um lado, a incorporação de PCM não encapsulado melhora o desempenho das argamassas à ação de gelo-degelo. Por outro lado, a incorporação de PCM em argamassas expostas a elevadas temperaturas mantém um comportamento semelhante ao das argamassas de referência (0\% PCM). Assim, a incorporação de 10\% de PCM pode ser considerada uma solução ideal, pois leva a um melhor desempenho geral ao considerar ambos os comportamentos. 


\section{AGRADECIMENTOS}

Os autores desejam agradecer o apoio financeiro fornecido pelo Centro de Território, Ambiente e Construção da Universidade do Minho e pela Fundação para a Ciência e Tecnologia (FCT), através da bolsa de pósdoutoramento CTAC/UID/ECI/04047/2013-UM.7.18.

\section{BIBLIOGRAFIA}

[1] SAFFARI M., PISELLI C., GRACIA A., et al., Thermal stress reduction in cool roof membranes using phase change materials (PCM), Energy and Buildings, v. 158, pp. 1097-1105, Jan. 2018.

[2] PACHTA V., TRIANTAFYLLAKI S., STEFANIDOU M., Performance of lime-based mortars at elevated temperatures, Construction and Building Materials, v. 189, pp. 576-584, Nov. 2018.

[3] EZZIANE M., KADRI T., MOLEZ L., et al., High temperature behaviour of polypropylene fibres reinforced mortars, Fire Safety Journal, v. 71, pp. 324-331, Jan. 2015.

[4] CUNHA S., AGUIAR J.B., PACHECO-TORGAL F., Effect of temperature on mortars with incorporation of phase change materials, Construction and Building Materials, v. 98 pp. 89-101, Nov. 2015.

[5] XUAN, W., CHEN, X., YANG, G., et al., Impact behavior and microstructure of cement mortar incorporating waste carpet fibers after exposure to high temperatures, Journal of Cleaner Production, v. 187, pp. 222-236, Jun. 2018.

[6] HORSZCZARUK, E., SIKORA, P., CENDROWSKI, K., et al., The effect of elevated temperature on the properties of cement mortars containing nanosilica and heavyweight aggregates, Construction and Building Materials, v. 137, pp. 420-431, Abr. 2017.

[7] SOARES, N., COSTA, J., GASPAR, A., et al., Review of passive PCM latent heat thermal energy storage systems towards buildings energy efficiency, Energy and Buildings, v. 59, pp. 82-103, Abr. 2013

[8] XIAO, H., WANG, W., GOH, S.H., Effectiveness study for fly ash cement improved marine clay, Construction and Building Materials, v. 157, pp. 1053-1064, Dez. 2017.

[9] CUNHA S., AGUIAR J.B., FERREIRA V., Eco-efficient mortars with incorporation of Phase Change Materials, Journal of Building Physics, v. 41, pp. 1-24, 2017.

[10] CUNHA S., LIMA M., AGUIAR J.B., Influence of adding phase change materials on the properties of cement mortars, Construction and Building Materials, v. 127, pp. 1-10, Nov. 2016.

[11] MARANI A., NEHDI M., Integrating phase change materials in construction materials: Critical review, Construction and Building Materials, v. 217, pp. 36-49, Ago. 2019.

[12] NAVARRO L., GRACIA A., CASTELL A., et al., PCM incorporation in a concrete core slab as a thermal storage and supply system: proof of concept, Energy and Buildings, v. 103, pp. 70-82, Set. 2015.

[13] AGUAYO, M., DAS, S., MAROLI, A., et al., The influence of microencapsulated phase change material (PCM) characteristics on the microstructure and strength of cementitious composites: experiments and finite element simulations, Cement and Concrete Composites, v. 73, pp. 29-41, Out. 2016.

[14] LECOMPTE, T., LE BIDEAU, P., GLOUANNEC, P., et al., Mechanical and thermo-physical behaviour of concretes and mortars containing phase change material, Energy and Buildings, v. 94 pp. 52-60, Maio 2015 .

[15] POMIANOWSKI, M., HEISELBERG, P., JENSEN, R., et al., A new experimental method to determine specific heat capacity of inhomogeneous concrete material with incorporated microencapsulated-PCM, $\mathrm{Ce}$ ment and Concrete Research, v. 55, pp. 22-34, Jan. 2014.

[16] JEONG, S., CHANG, S., WE, S., et al., Energy efficient thermal storage montmorillonite with phase change material containing exfoliated graphite nanoplatelets, Solar Energy Materials and Solar Cells, v. 139, pp. 65-70, Ago. 2015.

[17] LV, Y., ZHOU, W., JIN, W., Experimental and numerical study on thermal energy storage of polyethylene glycol/expanded graphite composite phase change material, Energy and Buildings, v. 111, pp. 242-252, Jan. 2016.

[18] WANG, X., YU, H., LI, L., et al., Experimental assessment on a kind of composite wall incorporated with shape-stabilized phase change materials (SSPCMs), Energy and Buildings, v. 128, pp. 567-574, Set. 2016.

[19] CUI, H., MEMON, S., LIU, R., Development, mechanical properties and numerical simulation of macro encapsulated thermal energy storage concrete, Energy and Buildings, v. 96, pp. 162-174, Jun. 2015. 
[20] SUTTAPHAKDEE, P., DULSANG, N., LORWANISHPAISARN, N., et al., Optimizing mix proportion and properties of lightweight concrete incorporated phase change material paraffin/recycled concrete block composite, Construction and Building Materials, v. 127, pp. 475-483, Nov. 2016.

[21] OLIVER, A., Thermal characterization of gypsum boards with PCM included: Thermal energy storage in buildings through latent heat, Energy and Buildings, v. 48, pp. 1-7, Maio 2012.

[22] BAHRAR, M., DJAMAI, Z., MANKIBI, M., et al., Numerical and experimental study on the use of microencapsulated phase change materials (PCMs) in textile reinforced concrete panels for energy storage, Sustainable Cities and Society, v. 41, pp. 455-468, Ago. 2018.

[23] AHMAD, M., BONTEMPS, A., SALLÉE, H., et al., Experimental investigation and computer simulation of thermal behaviour of wallboards containing a phase change material, Energy and Buildings, v. 38, pp. 357-366, Abr. 2016.

[24] SANTOS, T., KOLOKOTRONI, M., HOPPER, N., et al., Experimental study on the performance of a new encapsulation panel for PCM's to be used in the PCM-Air heat exchanger, Energy Procedia, v. 161, pp. 352-359, Mar. 2019.

[25] CARDOSO, I., Aplicação de Microcápsulas de PCM em Materiais de Isolamento Térmico para Fatos de Protecção e Combate ao Fogo, Departamento de Engenharia Têxtil, Universidade do Minho, Guimarães, Portugal, 2006.

[26] SHILEI, L., NENG, Z., GUOHUI, F., "Impact of Phase Change Wall Room on Indoor Thermal Environment in winter", Energy and Buildings, v. 38, pp. 18-24, Jan. 2006.

[27] DARKWA, K., O'CALLAGHAN, P., TETLOW, D., "Phase-change drywalls in a passive-solar building", Applied Energy, v. 83, pp. 425-435, Maio 2006.

[28] LAI, C., CHEN, R., LIN, C., Heat transfer and thermal storage behaviour of gypsum boards incorporating micro-encapsulated PCM, Energy and Buildings, v. 42, pp. 1259-1266, Ago. 2010.

[29] CUNHA, S., ALVES, V., AGUIAR, J., et al., Use of phase change materials microcapsules in aerial lime and gypsum mortars, Cement Wapno Beton, Special Issue, pp. 17-21, 2012.

[30] CUNHA, S., AGUIAR, J., FERREIRA, V., et al., Influence of Adding Encapsulated Phase Change Materials in Aerial Lime based Mortars, Advanced Materials Research, v. 687, pp. 255-261, 2013.

[31] CUNHA, S., AGUIAR, J., FERREIRA, V., et al., Influence of the type of phase change materials microcapsules on the properties of lime-gypsum thermal mortars, Advanced Engineering Materials, v. 16, pp. 433-441, 2014.

[32] AHMAD, M., BONTEMPS, A., SALLÉE, H., et al., "Thermal Testing and Numerical Simulation of a Prototype Cell Using Light Wallboards Coupling Vacuum Isolation Panels and Phase Change Material", Energy and Buildings, v. 38, pp. 673-681, Jun. 2006.

[33] MEMON, S.A., Phase change materials integrated in building walls: A state of the art review, Renewable and Sustainable Energy Reviews, v. 31, pp. 870-906, Mar. 2014.

[34] HAWES, D.W., BANU, D., FELDMAN, D., Latent heat storage in concrete, Solar Energy Materials, v. 19, pp. 335-348, Nov. 1989.

[35] REGIN A., SOLANKI S., SAINI J., Heat transfer characteristics of thermal energy storage system using PCM capsules: A review, Renewable and Sustainable Energy Reviews, Vol. 12, pp. 2438-2458, Dez. 2008.

[36] CABEZA, L., CASTELL, A., BARRENECHE, C., et al., Materials used as PCM in thermal energy storage in buildings: A review, Renewable and Sustainable Energy Reviews, v. 15, pp. 1675-1695, Abr. 2011.

[37] CUNHA S., AGUIAR J.B., TADEU, A., Thermal performance and cost analysis of PCM mortars based in different binders, Construction and Building Materials, v. 122, pp. 637-648, Set. 2016.

[38] CUNHA S., AGUIAR J.B., FERREIRA V.M., et al., Mortars Based in different binders with incorporation of phase change materials: Physical and mechanical properties, European Journal of Environmental and Civil Engineering, v. 19, pp. 1216-1233, 2015.

[39] CUNHA, S., AGUIAR, J.B., FERREIRA V., Eco-efficient mortars with incorporation of Phase Change Materials, Journal of Building Physics, v. 41, pp. 1-24, 2017.

[40] INSTITUTO PORTUGUÊS DA QUALIDADE (IPQ), NP EN 998-1, Especificações de argamassas para alvenarias - Parte 1: Argamassas para rebocos interiores e exteriores, 2010.

[41] EUROPEAN COMMITTEE FOR STANDARDIZATION (CEN), EN 1015-3:2004, Methods of test for mortar for masonry - Part 3: Determination of consistence of fresh mortar (by flow table), 2004. 
[42] EUROPEAN COMMITTEE FOR STANDARDIZATION (CEN), EN 1015-18:2002, Methods of test for mortar for masonry - Part 18: Determination of water absorption coefficient due to capillary action of hardened mortar, 2002.

[43] LABORATÓRIO NACIONAL DE ENGENHARIA CIVIL (LNEC), Especificação E 394, Betões - Determinação da absorção de água por imersão, 1993.

[44] EUROPEAN COMMITTEE FOR STANDARDIZATION (CEN), EN 1015-11:1999, Methods of test for mortar for masonry - Part 11: Determination of flexural and compressive strength of hardened mortar, 1999.

[45] EUROPEAN COMMITTEE FOR STANDARDIZATION (CEN), CEN/TS 12390-9:2006, Testing hardened concrete - Part 9: Freeze-thaw resistance, 2006.

[46] ANJOS, M., CAMÕES, A., JESUS, C., et al., Hydration assessment of cement pastes with high levels of mineral additions, Engenharia Civil UM, v. 44, pp. 41-58, 2012.

[47] BHATTY, J.I., REID, K.J., Use of thermal analysis in the hydration studies of a type 1 portland cement produced from mineral tailings, Thermochimica Acta, v. 91, pp. 95-105, Set. 1985.

[48] ALARCON-RUIZ, L., PLATRET, G., MASSIEU, E., et al., The use of thermal analysis in assessing the effect of temperature on a cement paste, Cement and Concrete Research, v. 35, pp. 609-661, Mar. 2005.

[49] BAERT, G., HOSTE, S., SCHUTTER, G., et al., Reactivity of fly ash in cement paste studied by means of thermogravimetry and isothermal calorimetry, Journal of Thermal Analysis and Calorimetry, v. 94, pp. 485-492, 2008.

[50] Rubitherm, RT22HC, http://www.rubitherm.eu/en/index.php/productcategory/organische-pcm-rt. Accessed in February 2019.

[51] LION, M., SKOCZYLAS, F., LAFHAJ, Z., et al., Experimental study on a mortar. Temperature effects on porosity and permeability. Residual properties or direct measurements under temperature, Cement and Concrete Research, v. 35, pp. 1937-1942, Out. 2005.

[52] YAZICI, S., SEZER, Í., SENGÜL, H., The effect of high temperature on the compressive strength of mortars, Construction and Building Materials, v. 35, pp. 97-100, Out. 2012.

[53] AYDIN, S., BARADAN, B., Effect of pumice and fly ash incorporation on high temperature, Cement and Concrete Research, v. 37, pp. 988-995, Jun. 2007.

[54] TAYLOR, H.F.W., Cement chemistry, Thomas Telford Publishing 1997.

\section{ORCID}

Sandra Cunha

Marisa Silva

José Aguiar https://orcid.org/0000-0002-6384-1355

https://orcid.org/0000-0002-8005-2964

https://orcid.org/0000-0003-3954-5721 